mit der ATP-Bildung. Die Reaktionsraten des Austausches sind zwar wesentlich kleiner als bei der Phosphorylierung im Licht und den bisher bekannt gewordenen ATP-ase-Reaktionen in Chloroplasten $\left(\mathrm{J}_{\mathrm{A}}\right.$ GENDORF und URIBE ${ }^{15}$ ). Die Austauschreaktion verläuft unter ähnlichen Bedingungen wie der lichtinduzierte ATP $-\mathrm{P}_{\mathrm{a}}$-Austausch (Carmeli und Avron ${ }^{8}$ ) und wie die chemiosmotische Phosphorylierung. Die Induktion der Austauschreaktion durch den SäureBase-Übergang scheint analog zu ihrer Induktion durch Licht zu sein. Von besonderem Interesse ist die Tatsache, daß auch ohne $p_{\mathrm{H}}$-Wechsel oder Lichtinduktion eine nur durch DTT bewirkte Austauschreaktion erscheint.

Zusammenfassend kann gesagt werden, daß Chloroplasten die Fähigkeit haben, einen ATP $-\mathrm{P}_{\mathrm{a}}$.

15 A. T. JAGendorf u. E. Uribe, in: Energy conversion by the photosynthetic apparatus, Brookhaven Symposium 19, 1967, p. 215.
Austausch zu katalysieren, welcher entweder durch Licht, durch einen Säure-Base-Wechsel oder durch ein starkes Reduktionsmittel induziert wird. In allen Fällen könnte angenommen werden, daß die Bildung eines primären, energiereichen Zustandes oder Zwischenproduktes in Chloroplasten die Voraussetzung für den Beginn der Austauschreaktion darstellt. Die Ähnlichkeit im Kofaktorenbedürfnis und in der Wirkung von Ammoniumionen als Entkoppler lassen vermuten, daß zwischen der durch Licht, durch ein Reduktionsmittel bzw. durch einen $p_{\mathrm{H}}$-Wechsel induzierten Austauschreaktion und der Photophosphorylierung bzw. der chemiosmotischen Phosphorylierung enge Zusammenhänge bestehen.

Wir danken Frau M. Sсносн für die gewissenhafte technische Mithilfe bei den Versuchen und dem Schweizerischen Nationalfonds für wissenschaftliche Forschung für die großzügige finanzielle Unterstützung.

\title{
Copper Replacement of Magnesium in the Chlorophylls and Bacteriochlorophyll
}

\author{
W. S. KIM \\ Exobiology Division, Ames Research Center, NASA, Moffett Field, Calif. \\ (Z. Naturforschg. 22 b, 1054-1061 [1967]; eingegangen am 24. Januar 1967)
}

\begin{abstract}
Copper chelates of chlorophylls "a" and " $b$ " and an oxidized form of bacteriochlorophyll "a" were prepared and separated by an improved method of column and thin-layer chromatography, and their physical properties and thermodynamics involved in the primary metal replacement reaction were studied. In glacial acetic acid the $\mathrm{Mg}$ (II) ions of the photosynthetic pigments were replaced rapidly by $\mathrm{Cu}$ (II) ions at $40-100^{\circ}$ and profound physical changes were noted in the chelation products. Copper chelates were not fluorescent while their parent pigments and pheophytins were. A general lowering of absorbance and a blue shift of absorption maxima were observed with the copper complexes. The molar absorptivity values of copper chelates were determined by the metallic microtitration method and the direct analysis of chelated copper by the oxalyldihydrazide $(\mathrm{ODH})$ of copper method. In the present assay, the primary reaction of copper replacement of $\mathrm{Mg}$ (II) in the 3 photosynthetic pigments was the bimolecular $\mathrm{S}_{\mathrm{E}^{2}}$ type. The primary reaction lasted only a short time $(1-5 \mathrm{~min})$ at temperatures of $40-90^{\circ}$, and the higher the temperature, the larger the constants of the bimolecular reaction became. On longer treatment, the metal replacement reaction was complicated by the increasing content of pheophytin. The reaction rate constants became progressively smaller in the order of chlorophyll "a" - "b"-bacteriochlorophyll "a". At $70^{\circ}$ the half lives of $20 \mu \mathrm{M}$ chlorophylls "a" and " $\mathrm{b}$ " and bacteriochlorophyll "a" for the copper replacement were 1.2, 15.2, and 117.4 minutes, respectively. Based on transition state theory, some thermodynamic constants relevant to this primary metal substitution reaction at various temperatures were calculated, and the possible mechanism involved were discussed.
\end{abstract}

Copper chelate of chlorophyll "a" (Cu-CHL "a") * and "b" (Cu-CHL "b") was recently prepared from purified pheophytins $\left(\Phi \Phi_{\mathrm{S}}\right)$, and physicochemical studies of these derivatives have already been re-

* Abbreviations will be used in the text; CHL, chlorophyll; BCHL, bacteriochlorophyll "a"; Cu-CHL, copper-chelated chlorophyll; Cu-BCHL, copper-chelate of an oxidized form of BCHL; $\Phi \Phi(\mathrm{s})$, pheophytin (s).

1 A. N. Sidorov and A. N. Terenin, Opt. Spectr. (USSR) (English Transl.) 8, 254 [1960]. ported ${ }^{1-4}$. However, detailed methods for preparing the purifying these complexes are lacking, as are comparative physical data, such as absorptivity and thermodynamics involved in the replacement reaction

2 A. G. Tweet, G. L. Gaines, Jr., and W. D. Bellamy, Nature [London] 202, 696 [1964].

3 I. L. Kukhkevich and A. I. Bulyak, Urr. Khim. Zh. 31, 943 [1965] ; C. A. 64, 2326 d.

4 B. D. Berezin and N. I. Sosnikova, Zh. Fiz. Khim. 39, 1348 [1965] ; C. A. 63, 8651 c. 
of these pigments. While most copper replacement studies have been made with the relatively stable porphyrins ${ }^{5-7}$, little work has been done with intact photosynthetic pigments, especially with bacteriochlorophyll (BCHL).

It is well known that the $\mathrm{Mg}$ (II) ion of a CHL molecule is easily replaced by two hydrogen ions in dilute acid, yielding a $\Phi \Phi$, while the $\mathrm{Cu}$ (II) ion is readily chelated in glacial acetic acid ${ }^{1}$. It will then be interesting to study the kinetics of copper replacement of $\mathrm{Mg}$ (II) of the photosynthetic pigments in glacial acetic acid to learn (1) whether the metal replacement takes place by a direct bimolecular reaction, $\mathrm{PMg}+\mathrm{Cu}^{2 \oplus} \rightleftarrows \mathrm{PCu}+\mathrm{Mg}^{2 \oplus}$, following a $\mathrm{S}_{\mathrm{E}^{2}}$ mechanism, or by the two step reaction,

$$
\begin{aligned}
& \mathrm{PMg}+2 \mathrm{H}^{\oplus} \rightleftarrows \mathrm{PH}_{2}+\mathrm{Mg}^{2 \oplus} ; \\
& \mathrm{PH}_{2}+\mathrm{Cu}^{2 \oplus} \rightleftarrows \mathrm{PCu}+2 \mathrm{H}^{\oplus}
\end{aligned}
$$

following a $\mathrm{S}_{\mathrm{E}^{1}}$ mechanism (here, $\mathrm{PMg}$ and PCu indicate, respectively, the photosynthetic pigments chelated with $\mathrm{Mg}(\mathrm{II})$ and $\mathrm{Cu}(\mathrm{II})$ and $\mathrm{PH}_{2}=\Phi \Phi$ ) and (2) whether different photosynthetic pigments react differently in terms of thermodynamics.

This paper presents (1) detailed methods of preparing and separating Cu-CHL "a", Cu-CHL "b" and the copper chelate of an oxidized form of BCHL (Cu-BCHL), (2) chromatography and absorbance of the copper complexes in relation to the parent pigments in various solvent systems, (3) some thermodynamic quantities involved in the transition state of the metal replacement, and (4) the possible mechanism of the primary reaction of the metal replacement with 3 common photosynthetic pigments.

\section{Materials and Methods}

\section{Extraction and chromatography of photosynthetic pigments}

Chlorophylls "a" and "b" were extracted with acetone from frozen spinach leaves ground in a blender. The photosynthetic bacteria, Rhodospirillum rubrum (ATCC No. 277), were cultured in tripticase soy broth and harvested, and BCHL was extracted as previously described ${ }^{8}$. The acetone solutions of crude plant or bacterial extracts were reduced to a small volume for fractional separation by column or thin-layer chromatography (TLC).

5 W. S. Caughey and A. H. Corwin, J. Amer. chem. Soc. 77, 1509 [1955].

6 J. E. Falk and R. S. Nyholm, in: A. Albert, G. M. Badger, and C. W. Shoppes (Eds.), Current Trends in Heterocyclic Chemistry, Butterworths, London 1958, p. 130.
A dry-packed column $(2.5 \times 20 \mathrm{~cm})$ was used for the column chromatography. About $100 \mathrm{~g}$ of Kieselguhr G (Brinkman Instr. Inc., N.Y.) was well suspended in $100 \mathrm{ml}$ of petroleum ether $\left(30-60^{\circ}, \mathrm{bp}\right)$ containing $5 \mathrm{ml}$ of triolein. It was then filtered, dried in the air, and powdered in a ball mill. Gentle suction was applied after a small amount $(2-3 \mathrm{ml})$ of sample was placed on the column. A mixed solvent system containing methanol, acetone, and water in a $6: 2: 1$ ratio (v/v) was then passed into the column. Exactly the same system was used in preparing the $7 \times 7$ inch thinlayer plates for the preparation of smaller amounts of photosynthetic pigments.

For the preparation and further analyses of the pigments and derivatives, thin-layer plates of diatomaceous earth, either powdered Gas Chrom $\mathrm{P}$ or Adsorbosil mixed with $25 \%$ of $\mathrm{CaSO}_{4}$ (both from Applied Sci. Lab. Inc., $\mathrm{Pa}$.), were used with various solvent systems (Table 1).

\section{Fluorescence and absorbance analysis}

For fluorometric analysis, a Baird Atomic Fluorospec of expanded wavelength, equipped with a red-sensitive tube (RCA 7102), was used in addition to the regular detector (IP 28). The wavelengths of excitation and emission were calibrated using a Neon Pen-ray lamp supplied by Baird Atomic. All the solvents used for the analysis were fluorometric grade purchased from the Harleco Sci. Products, Calif.

Absorption spectra of the photosynthetic pigments, $\Phi \Phi \mathrm{s}$, and copper chelates were obtained with either a Cary 14 or a HITACHI 139 spectrophotometer. The wavelengths as well as absorbance of the two instruments agreed closely.

\section{Copper chelates - preparation, isolation, and quantitation}

To examine the effect of heat upon degradation, intact photosynthetic pigments were heated at $100^{\circ}$ in glacial acetic acid. After 15 minutes at $100^{\circ}$ all 3 pigments were converted to $\Phi \Phi$ s without noticeable degradation as determined by TLC.

Copper chelation of these pigments was easily achieved by a $10-15$ minute heating $\left(100^{\circ}\right)$ of the mixture of a pigment and copper acetate in glacial acetic acid with an approximate molar ratio of $1: 5$. Single species of copper chelates with a trace amount of unreacted $\Phi \Phi$ appeared on a thin-layer plate. For routine analyses, $2-3 \mathrm{mg}$ of purified pigments were used for the chelation. Heated samples were vacuumdried, taken up in a small amount of cold ether and passed through a dry-packed Adsorbosil column to remove the copper residues. The filtrate was reduced in volume and the copper complex was further purified

\footnotetext{
7 J. W. Barnes and G. D. Dorough, J. Amer. chem. Soc. 72 , 4045 [1950].

8 W. S. KIM, Biochim. biophysica Acta [Amsterdam] 112 , 392 [1966].
} 


\begin{tabular}{|c|c|c|c|c|c|c|c|c|c|}
\hline \multirow{2}{*}{$\begin{array}{c}\text { TLC } \\
\text { sytem }\end{array}$} & \multirow[b]{2}{*}{ CHL-a } & \multirow[b]{2}{*}{$\Phi \Phi$-a } & \multirow[b]{2}{*}{$\mathrm{Cu}-\mathrm{CHL}$, , a } & \multicolumn{3}{|c|}{ Migration relative to $\Phi \Phi$-a } & \multirow[b]{2}{*}{ BCHL } & \multirow[b]{2}{*}{$\Phi \Phi-\mathrm{BCHL}$} & \multirow[b]{2}{*}{$\mathrm{Cu}-\mathrm{BCHL}$} \\
\hline & & & & CHL-b & $\Phi \Phi-\mathrm{b}$ & $\mathrm{Cu}-\mathrm{CHL}, \mathrm{b}^{\prime \prime}$ & & & \\
\hline 1 & 4.00 & 1.00 & 1.50 & 6.10 & 1.10 & 2.00 & 6.70 & 1.90 & 2.30 \\
\hline 2 & 0.71 & 1.00 & 0.37 & 0.22 & 0.57 & 0.46 & 0 & 0.40 & 0.28 \\
\hline 3 & 1.60 & 1.00 & 1.55 & 1.62 & 1.33 & 1.51 & 1.58 & 1.45 & 1.55 \\
\hline
\end{tabular}

Table 1. Three TLC systems applied to the separation of the photosynthetic pigments, pheophytins, and copper pheohytins. System 1: Plate was coated with Kieselguhr G (0.5 ml thicknss) impregnated with $5 \%(\mathrm{v} / \mathrm{v})$ triolein and the TCL was run with a mixed solvent of methanol, acetone, and water in a ratio of $6: 2: 1$ (v/v); System 2: Plate was coated with Adsorbosil $\left(0.5 \mathrm{~mm}\right.$ thickness) mixed with $25 \%$ (w/v) of $\mathrm{CaSO}_{4}$ and TCL run with a mixed solvent of petroleum ether $\left(30-60^{\circ} \mathrm{bp}\right)$, ethyl ether, and glacial acetic acid in a $100: 50: 1$ (v/v) ratio; System 3: Plate was covered with powdered $0.5 \mathrm{ml}$ thick diatomaceous earth (Gas Chrom P) and TCL run with the same solvent as System 1.

by preparative TLC on various plates (Table 1 ). The bluish-green copper chelate band was eluted with ether or other solvents for further analysis. Two methods for quantitation of the copper chelates were applied; the direct analysis of the copper content by oxalyldihydrazide $(\mathrm{ODH})$ and the indirect metallic microtitration of pheophytins, a method originally described by OLiver and Rawlinson ${ }^{9}$ and modified recently by $\mathrm{Krm}^{10}$.

\section{Kinetics and thermodynamics of the metallic substitution reaction}

To measure the reaction rate, tubes containing equimolar $(20 \mu \mathrm{M})$ pigment and copper acetate and their acetate blanks were placed in a constant temperature bath for a definite time. A graduated $15 \mathrm{ml}$ pyrex tube containing 20 nmole of copper acetate in $1.0 \mathrm{ml}$ of glacial acetic acid and a tube containing only acetic acid were placed in the bath with their tops open. After $2-3$ minutes of equilibration, 20 nmoles of pigments dissolved in $10 \mu \mathrm{l}$ acetone was added to each of the tubes. A timer was started simultaneously with the addition of the pigment, and after a definite period of heating (Fig. 6), tubes were transferred quickly to an ice bath. The volume of the tubes was brought to 3.0 $\mathrm{ml}$ at $25^{\circ}$ by adding glacial acetic acid, and the difference spectra were run. The increase of absorbance of the newly developing visible band of complex $(650$ $\mathrm{m} \mu$ for Cu-CHL "a", $630 \mathrm{~m} \mu$ for Cu-CHL "b", and $663 \mathrm{~m} \mu$ for $\mathrm{Cu}-\mathrm{BCHL}$ ) was traced and the reaction rates and order of the reaction were determined from data obtained at various times and temperatures. Thermodynamic constants relevant to the transition state of the metallic substitution were calculated using the Arrhenius equation ${ }^{11}$, Eyring's equation ${ }^{12}$, and the second law of thermodynamics ${ }^{11,13}$.

${ }^{9}$ I. T. Oliver and W. A. Rawlinson, Biochem. J. 49, 157 [1951].

10 W. S. Kim, Analytic Chem. Unpublished data.

11 F. Daniels and R. A. Alberty, Physical Chemistry, John Wiley, New York 1962, p. 271, 294.

12 H. Eyring, J. chem. Physics 3, 107 [1935].

13 A. A. Frost and R. G. Pearson, Kinetics and Mechanism, John Wiley, New York 1962, p. 77, 123.

\section{Results}

\section{Extraction and separation of pigments by chromatography}

Detailed procedures for extracting and separating the photosynthetic pigments from spinach and bacteria are shown in Fig. 1, and the separation

EXTRACTION \& SEPARATION OF CHLOROPHYLLS

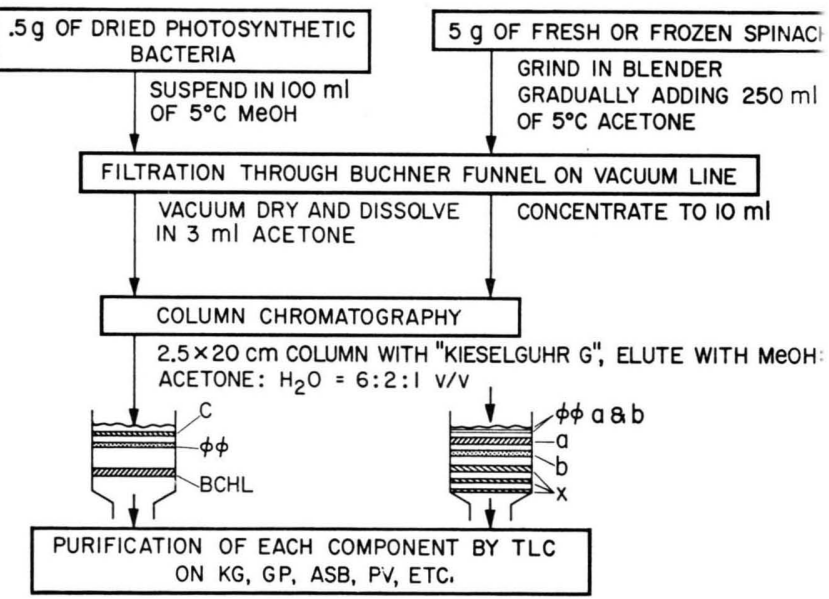

Fig. 1. Scheme of extraction and separation of the photosynthetic pigments and carotenoids from spinach and bacterial cells of Rhodospirillum rubrum. $C$, carotenoid; $\Phi \Phi$, pheophytin; BCHL, bacteriochlorophyll; a, chlorophyll „,a“; b, chlorophyll "b"; x, xanthophylls; KG, Kieselguhr G ; GP, Gas Chrom

P; ASB, Adsorbosil; PV, Polyvinyl thin-layer materials.

patterns of parent pigments, $\Phi \Phi \mathrm{s}$, and copper chelates on three different TLC systems are illustrated in Table 1. On the Kieselguhr column 3 discrete bands were separated from the bacterial extract and 5 main bands from spinach. On TLC of the same system, further separation was noted; the bacterial extract was separated into 2 carotenoids (pink), a $\Phi \Phi$ (violet pink) and a thick BCHL (blue) respective to the origins, while the spinach extract was separated into $\Phi \Phi$ "a" (gray-green), $\Phi \Phi$ "b" (yellow), CHL 
„a" (deep green), CHL "b" (light green), and 3 bands of xanthophylls (yellow). Further purification could be achieved by various TLC methods (Table 1). Single pigment bands from the TLC were eluted with cold ethyl ether.

\section{Fluorescence and absorbance of photosynthetic pigments and their copper complexes}

The spectra and maximal wavelengths of fluorescence and excitation of all the photosynthetic pigments and their $\Phi \Phi_{\mathrm{S}}$ in various solvents agreed closely with data published earlier ${ }^{8,14}$. None of the copper derivatives of the 3 photosynthetic pigments were fluorescent in any of the 15 common organic solvents tested. In methanol only $\mathrm{Cu}$-CHL "a" was soluble, while Cu-CHL "b" and Cu-BCHL were insoluble.

Figs. 2, 3 and 4 show the absorption spectra of 3 photosynthetic pigments, $\Phi \Phi$ s and the copper chelates in ether. The absorptivities of the parent pigments and $\Phi \Phi_{\mathrm{S}}$ were determined by the fluorometric $\mathrm{Mg}$ analysis ${ }^{8}$ and copper titration method ${ }^{9}$, respectively, in conjunction with their absorption spectra. Table 2 presents the maximum absorption wavelength $\left(A_{\lambda_{\max }}\right)$ and the millimolar absorptivity $(\xi \mathrm{mM})$ of the major absorption bands of these pigments dissolved in ether. From Figs. 2, 3 and 4 and Table 2 it should be noted that the $A_{\lambda \max }$ of visible absorption peaks of all the copper complexes were

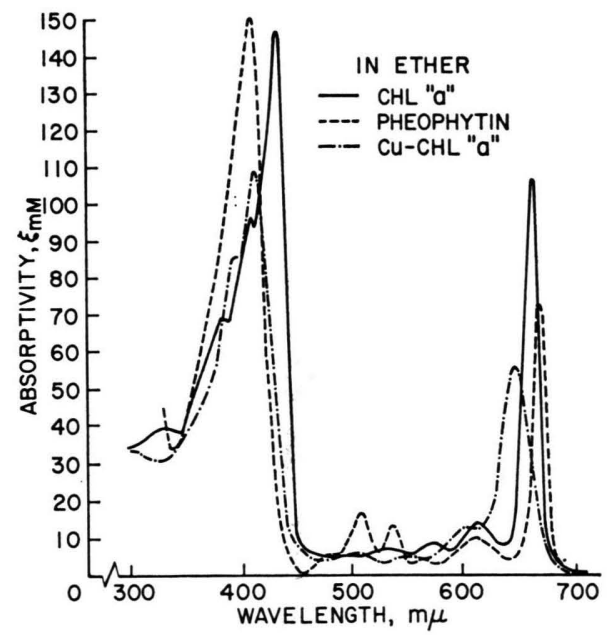

Fig. 2. Absorption spectra of purified chlorophyll "a" and its derivatives in ether. Note the blue shift of main absorption bands and reduction of absorptivity of red band of $\mathrm{Cu}-\mathrm{CHL}$ "a" relative to the parent pigment, CHL "a".

14 C. S. French, J. H. C. Smith, M. I. Virgin, and R. L. Airth, Plant Physiol. 31, 369 [1956].

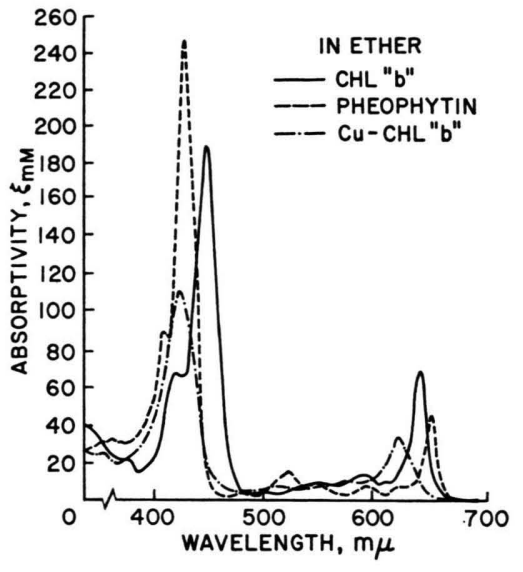

Fig. 3. Absorption spectra of chlorophyll "b" and its derivatives in ether. Note the blue shift of main absorption bands and reduction of absorptivity of the main bands of Cu-CHL "b" relative to the parent pigment, CHL „b".

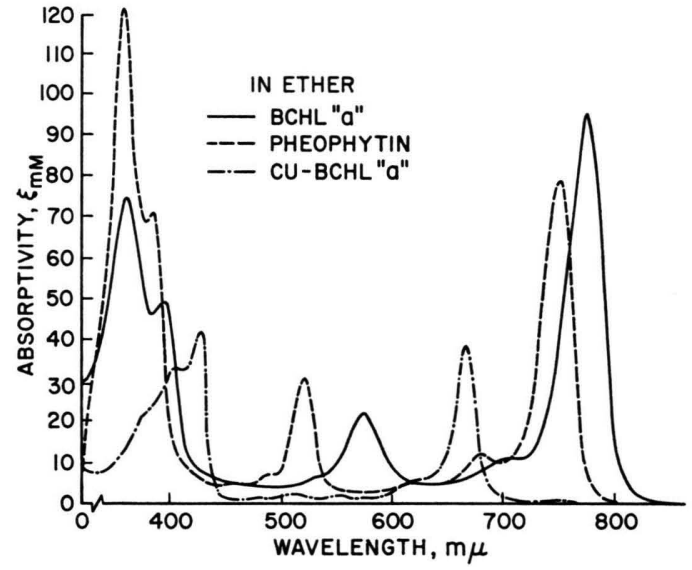

Fig. 4. Absorption spectra of bacteriochlorophyll "a" and its derivatives in ether. Note the shifts of Soret band of $\mathrm{Cu}$ BCHL toward red and red band toward blue and the marked reduction of absorptivity of main bands of the copper chelate relative to the parent BCHL "a" and its pheophytin. The ligand of $\mathrm{Cu}-\mathrm{BCHL}$ is an oxidized form of bacteriopheophytin.

shifted toward shorter wavelengths with respect to their $\mathrm{Mg}$ analogues, while the $\Phi \Phi$ peaks showed a bathochromic shift. The Soret bands of Cu-CHL "a" and " $b$ " also shifted to shorter wavelengths while the SoRET band of Cu-BCHL was shifted toward the red side. Table 3 lists the main absorption bands of copper chelates and their absorptivities in some common solvents. The solvent effects were observed by the changes in intensities of absorbance and the spectral position of absorption maxima; in glacial acetic acid the relative absorptivity values of major peaks were the smallest, and in pyridine the "redshifts" of the absorption maxima were the greatest. 


\begin{tabular}{|c|c|c|c|c|c|c|c|c|c|c|c|c|c|c|c|c|c|}
\hline \multicolumn{2}{|c|}{ CHL-a } & \multicolumn{2}{|c|}{$\Phi \Phi$-a } & \multicolumn{2}{|c|}{$\mathrm{Cu}-\mathrm{CHL}, \mathrm{a}^{\prime \prime}$} & \multicolumn{2}{|c|}{ CHL-b } & \multicolumn{2}{|c|}{$\Phi \Phi-\mathrm{b}$} & \multicolumn{2}{|c|}{$\mathrm{Cu}-\mathrm{CHL},, \mathrm{b}^{\prime \prime}$} & \multicolumn{2}{|c|}{ BCHL } & \multicolumn{2}{|c|}{$\Phi \Phi-\mathrm{BCHL}$} & \multicolumn{2}{|c|}{$\mathrm{Cu}-\mathrm{BCHL}$} \\
\hline 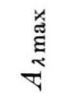 & $\underset{\text { wen }}{\Xi}$ & 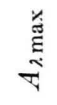 & $\underset{\text { gen }}{\sum_{1}}$ & 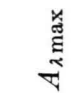 & $\sum_{\text {sen }}$ & 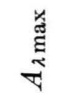 & 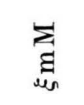 & 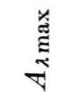 & $\underset{\text { wer }}{\stackrel{\sum}{\mid}}$ & 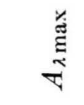 & $\sum_{\text {ser }}$ & & $\sum_{\text {sen }}$ & 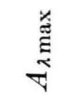 & $\sum_{\text {sen }}$ & 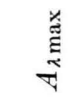 & $\sum_{\text {玉 }}$ \\
\hline 430 & 147.1 & 409 & 151.5 & 414 & 108.3 & 453 & 192.6 & 434 & 244.0 & 430 & 112.5 & 358 & 75.2 & 357 & 120.8 & 425 & 40.5 \\
\hline 662 & 112.9 & 667 & 73.1 & 648 & 58.5 & 645 & 68.3 & 653 & 47.5 & 626 & 35.6 & 770 & 98.7 & 750 & 73.1 & 666 & 35.5 \\
\hline
\end{tabular}

Table 2. Main absorption wavelength maxima $\left(A_{\lambda \max }\right)$ and the millimolar absorptivity $(\xi \mathrm{mM})$ of 3 photosynthetic pigments, pheophytins, and copper pheophytinates in ether.

\begin{tabular}{|c|c|c|c|c|c|c|c|c|c|c|c|c|}
\hline \multirow{2}{*}{$\begin{array}{l}\text { Copper } \\
\text { chelate }\end{array}$} & \multicolumn{2}{|c|}{ Ether } & \multicolumn{2}{|c|}{ Acetone } & \multicolumn{2}{|c|}{ Acetic acid } & \multicolumn{2}{|c|}{ Benzene } & \multicolumn{2}{|c|}{ Pyridine } & \multicolumn{2}{|c|}{$\mathrm{MeOH}$} \\
\hline & $A_{\lambda \max } *$ & $\xi \mathrm{mM} * *$ & $A_{\lambda \max }$ & $\xi \mathrm{m} M$ & $A_{\lambda \max }$ & $\xi \mathrm{mM}$ & $A_{\lambda \max }$ & $\xi \mathrm{mM}$ & $A_{\lambda \max }$ & $\xi \mathrm{mM}$ & $A_{\lambda \max }$ & $\xi \mathrm{mM}$ \\
\hline \multirow[t]{2}{*}{$\mathrm{Cu}-\mathrm{CHL}, \mathrm{a}^{\text {“" }}$} & 414 & 108.3 & 412 & 108 & 412 & 92 & 41 & 104.9 & 422 & 98.7 & 412 & 96.6 \\
\hline & 6 & & 6 & & 65 & 48 & 65 & 58 & 655 & 56.6 & 650 & 55.5 \\
\hline \multirow[t]{2}{*}{$\mathrm{CuCHL}, \mathrm{b}^{6 "}$} & 430 & 112.6 & 432 & 117.2 & 437 & 93.2 & 438 & 108.3 & 450 & 100.8 & - *** & - \\
\hline & 626 & 35.6 & 627 & 36.7 & 627 & 29.8 & 630 & 36.7 & 635 & 34.1 & - & - \\
\hline \multirow[t]{2}{*}{$\mathrm{Cu}-\mathrm{BCHL}, \mathrm{a}^{\prime \prime}$} & 425 & 40.5 & 428 & 42.0 & 428 & 31.1 & 432 & 38.0 & 435 & 39.0 & - & - \\
\hline & 666 & 35.5 & 665 & 36.1 & 672 & 30.8 & 672 & 36.4 & 675 & 36.3 & - & - \\
\hline
\end{tabular}

Table 3. Absorptivity of main absorption maxima of copper-chelated photosynthettic pigments in various solvents. * Wavelength of maximum absorption. ** Millimolar absorptivity. *** Both Cu-CHL "b" and Cu-BCHL "a" are insoluble.

\section{Determination of reaction rates}

Fig. 5 shows the difference spectra obtained from 3 photosynthetic pigments reacted with equimolar $(20 \mu \mathrm{M})$ copper acetate in glacial acetic acid at $100^{\circ}$ for a period of 10 minutes. The spectra were

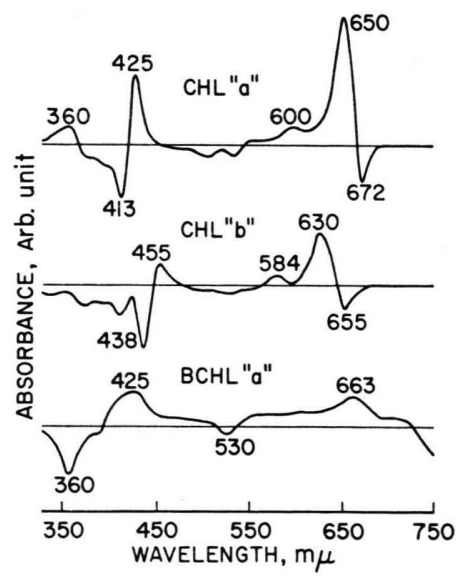

Fig. 5. Difference absorption spectra between copper complexes and photosynthetic pigment blanks in glacial acetic acid. Equimolar $(20 \mu \mathrm{M})$ mixture of a pigment and copper acetate in $3.0 \mathrm{ml}$ of glacial acetic acid was heated for $10 \mathrm{~min}$. at $100^{\circ}$. New outgrowth of absorption bands of SoRET and red peaks is evident. Note also pheophytination of CHL " $a$ " and "b" showing negative peaks at 672 and $655 \mathrm{~m} \mu$.

drawn using the reference blank which contained only the pigment and no copper. A prominent new visible band and a SoREt band were developed as the copper chelates formed. The development of visible red absorption peaks, $650 \mathrm{~m} \mu$ for $\mathrm{Cu}$-CHL „a", $630 \mathrm{~m} \mu$ of Cu-CHL "b", and $663 \mathrm{~m} \mu \mathrm{Cu}$ BCHL, was traced for the kinetic analysis. It is quite evident from the figure that the difference spectra of Cu-CHLs "a" and "b" indicate the demetallization showing negative peaks of 672 and $655 \mathrm{~m} \mu$, respectively. Although it is not shown in the figure the difference spectrum of Cu-BCHL developed a negative peak around $770 \mathrm{~m} \mu$ indicating that BCHL was still predominant over its $\Phi \Phi$.

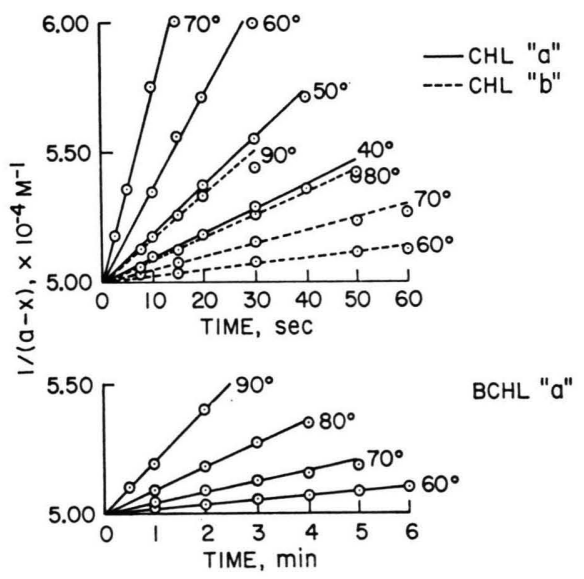

Fig. 6. Kinetics of copper chelation with 3 photosynthetic pig. ments. An equimolar $(20 \mu \mathrm{M})$ mixture of pigment and copper acetate was heated at temperatures and for times indicated; a, initial concentration of reactants; $x$, concentration of pig. ment reacted. 
When replacement reaction was followed for shorter time intervals $(1-5 \mathrm{~min}$.) at temperatures between $40-90^{\circ}$ instead of $100^{\circ}$, the mode of metal substitution reaction was bimolecular $\left(\mathrm{S}_{\mathrm{E}^{2}}\right)$ and the pseudo second order rate constants were calculated from the slope of the reciprocal of unreacted pigment versus reaction time at various temperatures (Fig. 6). Marked differences in reaction rate were noted among the three pigments. The rate decreased in the order: CHL "a" $>$ "b" $>$ BCHL. Although it is not indicated in Fig. 6, it was found that a longer treatment of the reaction mixtures at higher temperatures complicated the reaction owing to the formation of $\Phi \Phi_{\mathrm{S}}$, and the reaction no longer followed the second order.

The half lives of $20 \mu \mathrm{M}$ reactants at various temperatures were calculated and Fig. 7 shows the curves obtained from 3 complexing reactions. The rate constants and half lives of the equimolar reactants calculated are presented in Table 4.

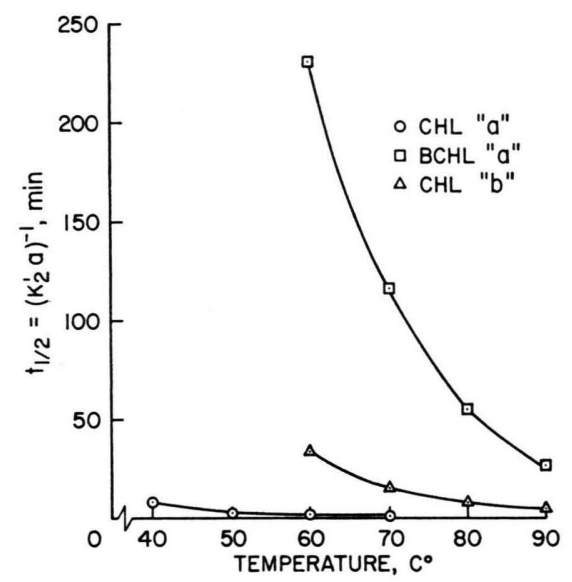

Fig. 7. Half life periods of $20 \mu \mathrm{M}$ photosynthetic pigments reacted with equimolar copper in acetic acid at different temperatures.

\section{Determination of thermodynamic quantities of the primary metal replacement reaction}

On the basis of the transition state theory of Eyring ${ }^{11}$ and using the empirical formula of ArRHENIUS ${ }^{12}$, the activation energy, $E_{\mathrm{a}}$, involved in the primary bimolecular reaction between the photosynthetic pigments and copper was determined. Fig. 8 is the plot between the logarithms of the pseudo second order rate constants, $k_{2}{ }^{\prime}$, and reciprocals of absolute temperature, 1/T. From the negative slopes, $E_{\text {a }}$ values were calculated and the activation enthalpy changes, $\Delta H^{\ddagger}$, were determined from the simplified

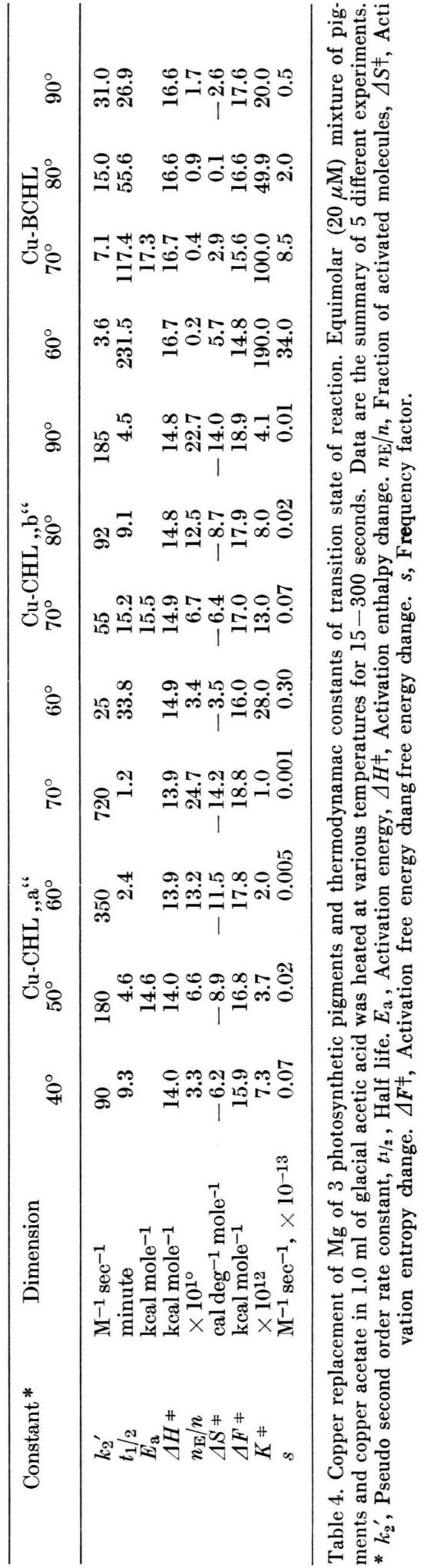




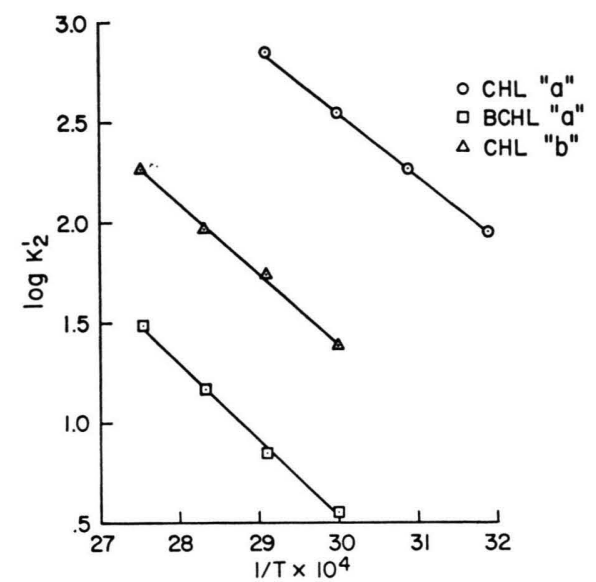

Fig. 8. Graphical determination of activation energy, $E_{\mathrm{a}}$ for reaction of equimolar $(20 \mu \mathrm{M})$ mixtures of photosynthetic pigments and copper.

formula, $E_{\mathrm{a}}=\Delta H^{\ddagger}+R T$ where $R$ is the gas constant. The MAxwelL-Boltzmann distribution law ${ }^{13}$ was used to calculate the fraction of activated molecules, $n_{\mathrm{E}} / n$. The values of $E_{\mathrm{a}}$ and $\Delta H^{\ddagger}$ were the smallest in the metal replacement of chlorophyll "a" and increased in the order: CHL „b" $<$ BCHL. The activation entropy change, $\Delta S^{\ddagger}$, and the activation equilibrium constant, $K^{\ddagger}$, increased progressively in the order: CHL "a" $<$ "b" $<$ BCHL, and decreased as the temperature increased, while the reverse was true with the activation free energy change, $\Delta F^{\ddagger}$. The magnitude of constant " $s$ " is often equated with the effective number of collisions that cause the bimolecular reactions ${ }^{12}$; in the present substitution experiments, " $s$ " values increased progressively in the order: CHL "a" $<$ "b" $<$ BCHL, and decreased as temperature increased. Similar experiments were repeated 5 times and data obtained were essentially similar. Typical data obtained from an experiment are summarized in Table 4.

\section{Discussion}

An earlier report ${ }^{15}$ that $\mathrm{Cu}$-BCHL was fluorescent was not repeatable. The revocation is consistent with earlier findings ${ }^{16}$ that no metallic porphyrins chelated with the first transition metals were fluorescent.

15 W. S. Kim and D. D. Feller, Federat. Proc. 25, 578 [1966]. 16 J. B. Allison and R. S. Becker, J. chem. Physics 32, 1410 [1960].

17 R. W. Livingston, Handbuch der Pflanzenzhysiologie, W. Ruhland (Ed.), 1, 1960, p. 830.

** W. D. Bellamy and N. R. Murty, Personal communication.
Metalloporphyrins chelated with closed-shell metal ions, such as $\mathrm{Mg}(\mathrm{II}), \mathrm{Ca}(\mathrm{II}), \mathrm{Zn}(\mathrm{II}), \mathrm{Cd}(\mathrm{II})$, $\mathrm{Ba}(\mathrm{II})$, etc., were fluorescent in the presence of a polar ligand, such as water ${ }^{17}$. The immediate quenching of the fluorescence of the photosynthetic pigments by copper replacement may then be due to the unpaired $3 \mathrm{~d}$ electron of the copper ion. The photo-excited $\pi$ electron may be paired off with the $3 \mathrm{~d}$ electron reaching the ground state without fluorescing.

Bellamy and Murty ** suggested that the two species of $\mathrm{Cu}$-CHL "a" isolated from their preparation might be caused by allomerization; the normal species absorbed maximally at 420 and $650 \mathrm{~m} \mu$ in ether with an absorptivity ratio of 1.30 while the allomerized form absorbed at 409 and $644 \mathrm{~m} \mu$ with the ratio of 1.43 . In the present experiment where intact photosynthetic pigments and copper acetate were heated in glacial acetic acid at $100^{\circ}$ for 10 to 15 minutes, only a single copper chelating band was isolated from 3 different TLC systems. In ether, the Cu-CHL "a" absorbed maximally at 414 and $648 \mathrm{~m} \mu$ (Table 3) and the ratio of absorptivity was as high as 1.85. The discrepancy between the two sets of data cannot be explained at the present time since critical structural analysis has not been carried out. It is highly unlikely the Cu-CHL " $a$ " prepared in thtis experiment was totally allomerized since the complex gave a positive reaction in phase test with $30 \% \mathrm{KOH}$.

The general tendency of reduction in intensity and shortening in wavelength of the major absorption bands of ocpper chelates relative to the $\mathrm{Mg}$ analogues may be related to the electronegativity of copper being higher (1.9) than that of $\mathrm{Mg}$ (1.2) as suggested by Gouterman ${ }^{18-20}$. Although no proof of the reaction mechanism is available, the tetrahydro form of BCHL may become oxidized to become the G-2 form ${ }^{8}$ which appears to be the 2 -acetyl 3,4-hydroxy chlorophyll "a" rather than the 2-acetyl chlorophyll "a" suggested earlier ${ }^{21}$. The G-2 component of BCHL absorbed maximally at 435 and $675 \mathrm{~m} \mu$ in ether while the unoxidized BCHL absorbed at 358 and $770 \mathrm{~m} \mu$. The absorption spec-

18 M. J. Gouterman, J. chem. Physics 30, 1139 [1959].

19 M. J. Gouterman, J. chem. Physics 33, 1523 [1960].

20 M. J. Gouterman, J. molecular Spectroscopy 6, 138 [1961].

21 H. Fischer and A.Stern, Die Chemie des Pyrrols, Vol. IL, 2, Akademische Verlagsgesellschaft, Leipzig 1940 b, p. 311. 
tra of $\mathrm{Cu}-\mathrm{BCHL}$ in ether showed the SonEt at 425 and the red maximum at $666 \mathrm{~m} \mu$ (Table 3 ). In view of the general shift of the absorption peaks to the blue side with both Cu-CHLs "a" and "b", it would be logical to assume that the ligand pigment of $\mathrm{Cu}$ BCHL could be the G-2 component rather than the intact BCHL. Experiments are in progress to confirm this possibility.

The Mg ion of CHL "a" does not replace the isotope ${ }^{28} \mathrm{Mg}$ in aqueous acetone ${ }^{22}$. The replacement of $\mathrm{Mg}$ with $\mathrm{Cu}$ ions in photosynthetic pigments was easily achieved in acetic acid especially at higher temperatures $\left(40-100^{\circ}\right)$. While the parent pigments were easily dissociated in dilute acid, the copper chelates were not dissociated in glacial acetic acid, conc. $\mathrm{HCl}$ or even conc. $\mathrm{H}_{2} \mathrm{SO}_{4}$ in room temperature. Only after a prolonged reflux in the latter acid or wet oxidation with perchloric acid was the copper ion released. This stability difference in the two classes of metalloporphyrins may be due primarily to the fact that $\mathrm{Cu}-\mathrm{N}$ bond is more covalent (79\%) than $\mathrm{Mg}-\mathrm{N}$ bond $(53 \%)$ as calculated from the electronegativity values of PAULING ${ }^{23}$.

The possibility of adding more ligands in the direction of the " $z$ " axis of the metal ion to the square $d^{9}$ copper complexes of the photosynthetic pigments may well be ruled out from the reported fact that a repulsive force of the filled $\mathrm{d}_{z^{2}}$ orbital is exerted through the " $z$ " axis, while the interaction of the porphyrin $\mathrm{N}$ atoms with the half-filled $\mathrm{d}_{x^{2}-y^{2}}$ orbital in the planar direction becomes much stronger ${ }^{24}$. This $1: 1$ stoichiometry of the metal-ligand binding ratio was further confirmed by the present experimental results that two sets of molar absorptivity values determined by metallic microtitration and the ODH copper analysis method were in good agreement.

The metal replacement of porphyrin molecules in solution may primarily depend upon the power of

22 S. Aronoff, Biochim. biophysica Acta [Amsterdam] 60, 193 [1962].

23 L. Pauling, The Nature of the Chemical Bond, Cornell Univ. Press, Ithaca 1945, N.Y. electrostatic attraction. Cu-CHL "a" has only one electron-seeking side chain, the 2-vinyl group, while "b" has two, the 2-vinyl and 3-formyl groups. Consequently the "b" molecule would cause a greater decrease in $\pi$ electron densities surrounding $\mathrm{N}$ atoms, thus reducing the electrostatic attraction of the copper ion ${ }^{25}$. This, in turn, would influence the reduction of the reaction rate, the increase of $\Delta S^{\ddagger}$, $E_{\mathrm{a}}, \Delta H^{\ddagger}, K^{\ddagger}$, and " $s$ " values, and the decrease of $\Delta F^{\ddagger}$ which is not spontaneous (Table 4). The lowest rate of copper replacement with BCHL cannot be explained on the basis of an electrophilic 2-acetyl group. As postulated earlier, the resulting $\mathrm{Cu}-\mathrm{BCHL}$ may in reality be the $\mathrm{Cu}-\mathrm{G}-2$ which may bear two hydroxyl groups at the 3 and $4 \beta$-carbon positions of the porphyrin nucleus, thus giving the complex 3 electron-withdrawing groups in contrast to 1 in $\mathrm{Cu}-\mathrm{CHL}$ "a" and 2 in Cu-CHL "b". However, there is no reason to believe that the electrostatic effect is the only cause of rate-limiting in the replacement reaction. Others, such as the geometry of planar space of the porphyrin molecules, steric hindrance, or the resonance energy encircling the 18-membered Simpson loop, many also affect the copper in such a way that the binding of $\mathrm{Cu}-\mathrm{N}$ could be influenced in different degrees. The relatively higher values of $\Delta S^{\ddagger}$ obtained with the formation of $\mathrm{Cu}$ BCHL appear to suggest a greater degree of structural distortion of the molecule.

\section{Acknowledgements}

The author wishes to thank Drs. L. P. ZiLL and R. D. Johnson and Mr. G. E. Pollock of Ames Research Center, who reviewed the manuscript and made many useful suggestions. Special thanks are directed to Prof. S. Annoff of Iowa State College, Ames, Iowa, for his helpful criticism on the manuscript and stimulating counsel.

24 L. E. ORGEL, An Introduction to Transition-Metal Chemistry; Ligand-Field-Theorem, Methuen, London 1960.

25 J. E. FALK, Porphyrins and Metallophorphyrins, Elsevier Publ. Co., New York 1964, p. 30. 